\title{
Sphk1 Expression and Survival Outcomes in Squamous Cell Carcinoma of the Oral Cavity
}

\author{
Brianna N. Harris ${ }^{*}$, Rizwan Masood, Uttam K. Sinha
}

Department of Otolaryngology and Pathology, Keck School of Medicine, University of Southern California, Los Angeles, USA. Email: *bnharris@usc.edu, masood@usc.edu, sinha@med.usc.edu

Received March 14 ${ }^{\text {th }}, 2013$; revised April 13 ${ }^{\text {th }}, 2013$; accepted April 20 ${ }^{\text {th }}, 2013$

Copyright (c) 2013 Brianna N. Harris et al. This is an open access article distributed under the Creative Commons Attribution License, which permits unrestricted use, distribution, and reproduction in any medium, provided the original work is properly cited.

\begin{abstract}
Sphingosine kinase 1 (SphK1) is an important mediator of apoptosis and the proliferation of cancer cells. It is upregulated in cells showing increasing radioresistance. Here we present the correlation between SphK1 expression and survival outcomes in patients with carcinoma of the oral cavity. A retrospective chart review was performed between January 2009 and August 2010 at the University of Southern California. Patients diagnosed with an advanced-stage primary tumor restricted to the oral cavity and a minimum follow-up of two years were included. Patients who did not receive post-operative radiation therapy were excluded. Eighteen patients met the inclusion criteria with 10 (55.6\%) patients demonstrating high expression of SphK1 and 8 (44.4\%) patients demonstrating a low-to-moderate expression of SphK1. Tumor recurrence occurred in 9 patients $(50.0 \%)$ : 5 patients $(27.8 \%)$ in the SphK1 $1^{\text {high }}$ cohort at a mean time to progression of 2.5 mo and 4 patients $(22.2 \%)$ in the SphK1 $1^{\text {low }}$ cohort at a mean time to progression of 11.0 mo $(\mathrm{p}=$ 0.023). Death occurred in 8 patients $(66.7 \%)$ in the SphK1 ${ }^{\text {high }}$ cohort and 3 patients $(16.7 \%)$ in the SphK1 $1^{\text {low }}$ cohort $(\mathrm{p}=$ 0.036). Higher expression of SphK1 correlates with greater radioresistance and poorer survival outcomes in patients with HNSCC of the oral cavity.
\end{abstract}

Keywords: Sphingosine Kinase 1; Squamous Cell Carcinoma, Radiation; Sphingolipids; Oral Cavity

\section{Introduction}

Head and neck squamous cell carcinoma (HNSCC) is the sixth most common cancer worldwide, accounting for approximately 500,000 new cases annually, with over 40,000 cases occurring in the United States [1]. Additionally, HNSCC is twice more common in men than in women, with a predilection for people over 50 years of age with a history of smoking and significant alcohol consumption [1]. Surgical resection and radiation therapy are the mainstays of treatment, achieving a $90 \%$ cure rate in stage I disease and a 70\% cure rate in stage II disease. As stage becomes more advanced, however, cure rates become dismal and tumor recurrence occurs in over $50 \%$ of patients [2]. Additionally, despite recent advances in therapy, the five-year survival rates have not improved for more than 3 decades, making HNSCC a major cause of morbidity and mortality [2]. The poor prognosis of advanced HNSCC increases the importance of determining new markers for targeted therapy. In particular, because

${ }^{*}$ Corresponding author. radiotherapy is a mainstay of treatment, increasing radiosensitivity is a promising new treatment strategy to decrease radiation-associated morbidity and to decrease overall mortality.

The sphingolipids sphingosine, ceramide, and sphingosine-1-phosphate (S1P) are important mediators of cell survival and proliferation in both normal cells and cancer cells. Ceramide and its derivative, sphingosine, promote apoptosis and inhibit cellular proliferation while S1P promotes proliferation and cell survival $[3,4]$. S1P activates multiple intracellular signaling cascades through binding specific G-protein coupled receptors, all of which are important mediators of angiogenesis, cell-to-cell adhesion, and tumor metastasis [5-9]. Sphingosine kinase (SphK) phosphorylates sphingosine to S1P, and is therefore an important regulator of the levels of ceramide, sphingosine, and S1P. In theory, upregulating SphK should upregulate S1P, and therefore enhance cell survival and proliferative capacity [10-13]. There are two isoenzymes of SphK, but SphK1 is known to be involved in carcinogenesis [14]. Sphingosine kinase 1 (SphK1) has previously been established as an important mediator of apoptosis, 
cell survival, and the proliferation of cancer cells. SphK1 is upregulated in a variety of human cancers including colon cancer, glioblastoma multiforme, breast cancer, lung cancer, and most recently in HNSCC [15-18].

Sphingolipids have also been implicated in tissue sensitivity to radiation. The following radiation treatment, ceramide levels within cells increase lead to activation of the intrinsic apoptotic pathway. Defects in ceramide production can lead to resistance to radiation-induced cell death [18-20]. S1P has been shown to decrease radiation sensitivity. SphK1, which increases S1P levels, was shown to be downregulated in radiosensitive prostate cancer cells following radiation treatment. There was no change in SphK1 levels in radioresistant cells, however [18,21-23].

Our previous research demonstrated that SphK1 expression is upregulated in primary HNSCC tumors, and that expression levels were higher in advanced stage and recurrent tumors [18]. We also demonstrated that decreasing SphK1 activity by siRNA knockdown reduced HNSCC cell proliferation and sensitized cells to radiation-induced death [18]. The objective of this paper is to present the correlation between SphK1 expression and survival outcomes in patients with oropharyngeal carcinoma.

\section{Methods}

All investigations were approved by the Institutional Review Board of the University of Southern CaliforniaUniversity Hospital (USC-UH), Los Angeles. A retrospective chart review of 18 patients who underwent surgery at the University of Southern California between January 2009 and August 2010 was performed. Patients with a minimum follow-up time of 2 years, and an advanced-stage primary tumor restricted to the oral cavity were included in the analysis. Patients who did not receive post-operative radiation or who did not complete radiation therapy were excluded. Demographic information, smoking status, post-operative chemoradiation, recurrence, and date of last follow-up or date of death were recorded. In the previously published paper, expression of SphK1 was determined by immunohistochemistry, Western blot, and real-time polymerase chain reaction (RT-PCR) [18]. The methods used will not be reproduced here. Sphingosine kinase expression was designated as high if protein expression was at least 2.7 times higher than that found in normal mucosa, and it was designated as low-to-moderate if it was at least 1.2 times higher than that found in normal mucosa [18]. The correlation of SphK1 expression levels to presence of HNSCC recurrence and survival outcomes were analyzed with $\mathrm{t}$ test and a Kaplan-Meier curve. A probability value of less than 0.05 was considered significant.

\section{Results}

Eighteen patients were identified who met the inclusion criteria with 10 (55.6\%) patients demonstrating high expression of SphK1 and 8 (44.4\%) patients demonstrating a low-to-moderate expression of SphK1. There were 10 male $(55.6 \%)$ and 8 female (44.4\%) with an average age of 62.6 years (range 26-83). Eleven patients (61.1\%) had a greater than 10-pack year history of smoking, while 6 patients (33.3\%) were nonsmokers. Smoking status could not be determined in one patient (5.6\%; Table 1). There was no difference between smoking status and level of SphK1 expression $(p=0.306)$. Mean tumor diameter at time of surgery was $3.54 \mathrm{~cm}$ (range $0.8 \mathrm{~cm}-8.0 \mathrm{~cm}$ ): mean tumor diameter was $4.16 \mathrm{~cm}$ (range $1.5-8.0 \mathrm{~cm}$ ) in SphK1high cohort and $2.76 \mathrm{~cm}$ (range $0.8-4.2 \mathrm{~cm}$ ) in the SphK1low cohort $(\mathrm{p}=0.083)$. Tumor recurrence occurred in 9 patients (50.0\%): 5 patients (27.8\%) in the SphK1high cohort at a mean time to progression of $2.5 \mathrm{mo}$ and 4 patients (22.2\%) in the SphK1low cohort at a mean time to progression of $11.0 \mathrm{mo}(\mathrm{p}=0.023)$. There was a statistically significant difference between the time of surgery to date of death or date of last follow-up between the SphK1high and SphK1low cohorts ( $p=0.028)$. There was no statistically significant difference between time of diagnosis and date of death or date of last follow-up between the two cohorts $(\mathrm{p}=0.055)$. Death occurred in 8 patients (66.7\%) in the SphK1high cohort and 3 patients $(16.7 \%)$ in the SphK1low cohort ( $p=0.036$; Figure 1). Smoking was inversely correlated to time of death $(\mathrm{r}=-0.27)$.

\section{Discussion}

The poor prognosis of advanced stage HNSCC makes the discovery of new cellular markers for targeted therapy imperative. In particular, because radiotherapy is a mainstay of treatment, discovering a mechanism to increase radiosensitivity while decreasing radiation-induced morbidity would be instrumental to decrease overall mortality in HNSCC [24]. Our previous research demonstrated that decreasing SphK1 activity by siRNA knockdown reduced HNSCC cell proliferation and sensitized cells to radiation-induced death [25]. We also demonstrated that higher SphK1 expression is associated with advanced stage and recurrent tumors in HNSCC [18]. In the present study there was a statistically significant difference between the two cohorts with respect to tumor recurrence. Four patients $(22.2 \%)$ in the SphK1 ${ }^{\text {high }}$ cohort showed disease recurrence at a mean time to progression of 2.5 mo whereas 4 patients (22.2\%) in the SphK $1^{\text {low }}$ cohort showed disease recurrence at a mean time to progression of $11.0 \mathrm{mo}(\mathrm{p}=0.023)$. The significantly shorter time between time of surgery to recurrence supports the hypothesis that higher SphK1 expression correlates with more aggressive tumorigenesis $[18,25]$. 
Table 1. Demographic data and significance between $\operatorname{SphK1} 1^{\text {high }}$ and SphK1 ${ }^{\text {low }}$ expression.

\begin{tabular}{|c|c|c|c|c|c|}
\hline & & Total & SphK1 $1^{\text {high }}$ & SphK1 $1^{\text {low }}$ & Significance (p) \\
\hline Age mean (range) & & $62.6(26-83)$ & $56.9(26-75)$ & $69.8(59-83)$ & 0.044 \\
\hline \multirow{3}{*}{ Gender } & Male & 10 (55.6\%) & 7 (38.9\%) & $3(16.7 \%)$ & \multirow{2}{*}{0.182} \\
\hline & Female & $8(44.4 \%)$ & $3(16.7 \%)$ & $5(27.8 \%)$ & \\
\hline & Caucasian & $10(55.6 \%)$ & 7 (38.9\%) & $3(16.7 \%)$ & 0.182 \\
\hline \multirow{3}{*}{ Race n, (\%) } & Hispanic & $3(16.7 \%)$ & $2(11.1 \%)$ & $1(5.6 \%)$ & 1.000 \\
\hline & African American & $2(11.1 \%)$ & $0(0.0 \%)$ & 2 (11.1\%) & 0.183 \\
\hline & Asian & $3(16.7 \%)$ & $1(5.6 \%)$ & 2 (11.1\%) & 0.559 \\
\hline Smoker n, (\%) & & $11(61.1 \%)$ & 7 (38.9\%) & $4(22.2 \%)$ & \multirow{2}{*}{0.484} \\
\hline Nonsmoker n, (\%) & & $6(33.3 \%)$ & $3(16.7 \%)$ & $3(16.7 \%)$ & \\
\hline \multirow{5}{*}{$\begin{array}{l}\text { Site of primary } \\
\text { Tumor n, (\%) }\end{array}$} & Tongue & $12(66.7 \%)$ & 8 (44.4\%) & $4(22.2 \%)$ & 0.321 \\
\hline & Buccal mucosa & $2(11.1 \%)$ & $0(0.0 \%)$ & $2(11.1 \%)$ & 0.183 \\
\hline & Alveolar Ridge & $2(11.1 \%)$ & $1(5.6 \%)$ & $1(5.6 \%)$ & 1.000 \\
\hline & Floor of Mouth & $1(5.6 \%)$ & $0(0.0 \%)$ & $1(5.6 \%)$ & 0.444 \\
\hline & Palate & $1(5.6 \%)$ & $1(5.6 \%)$ & $0(0.0 \%)$ & 1.000 \\
\hline
\end{tabular}

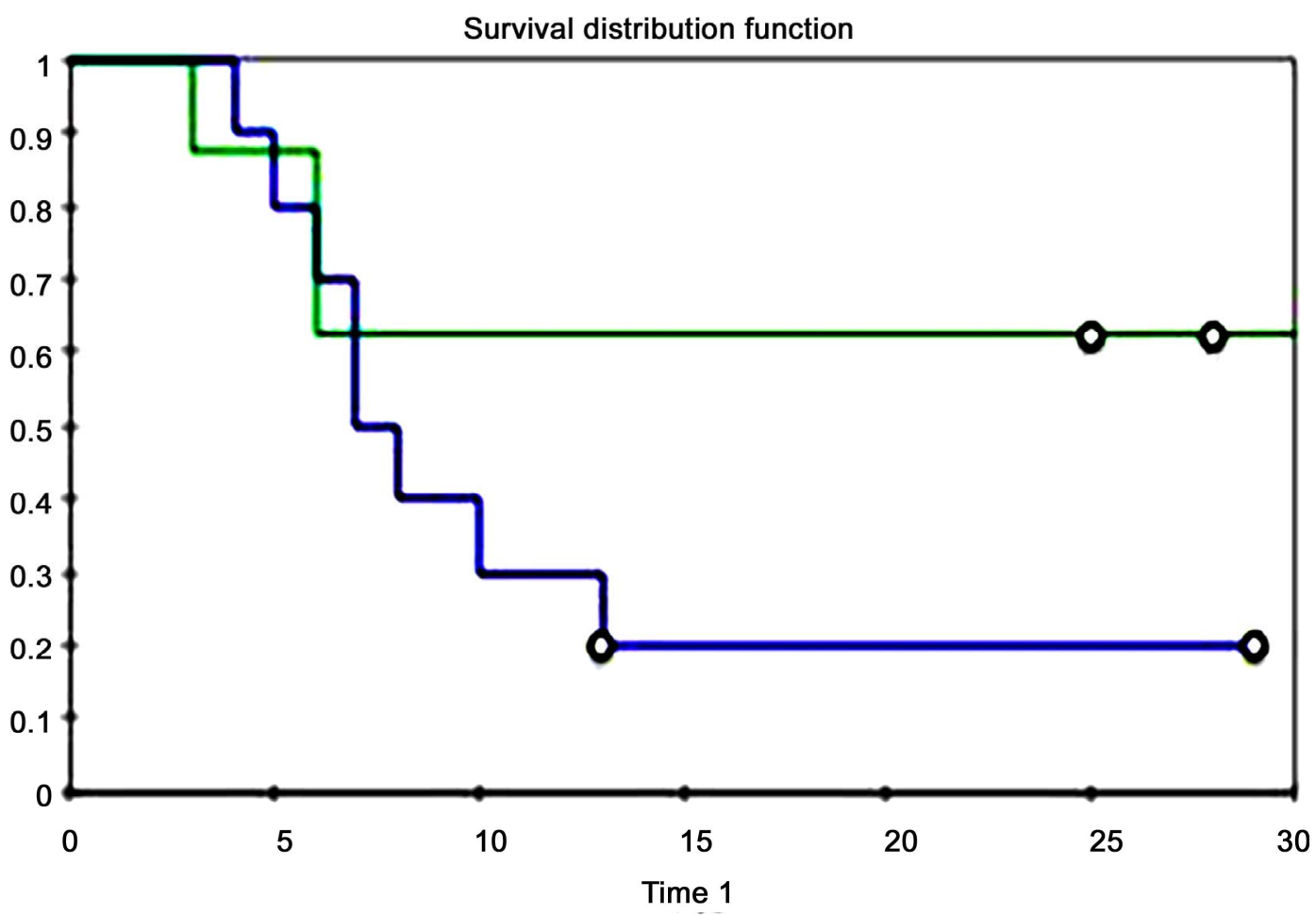

Time 1

Figure 1. Kaplan-Meier curve. The blue line (group 1) represents SphK1 ${ }^{\text {high }}$ while the green line (group 2) represents SphK1 ${ }^{\text {low. }}$.

Smoking is a known risk factor for HNSCC [26,27]. In the present study, eleven patients $(68.0 \%)$ had a greater than 10-pack year history of smoking, while 6 patients (28.0\%) were nonsmokers. There was no difference between smoking status and level of SphK1 expression ( $\mathrm{p}=$ 0.306). Smoking was inversely correlated to time of death, however $(r=-0.27)$. Smokers had a significantly shorter time to death than nonsmokers. No other studies have reported a correlation between SphK1 expression and tobacco use, but it offers an interesting hypothe- sis for the future.

Resistance to radiotherapy in advanced stage HNSCC through upregulation of SphK1 should lead to poorer survival outcomes. Of the three studies that have been done on SphK1 expression in HNSCC, only 1 other study looked at survival outcomes in patients. Facchinetti et al. studied survival outcomes in a group of 21 patients with Stage III SCC tumors from the oral cavity and found that positive SphK1 expression was associated with shorter survival time [28]. In the present study, 
death occurred in 8 patients $(66.7 \%)$ in the SphK1 ${ }^{\text {high }}$ cohort and 3 patients $(16.7 \%)$ in the $S p h K 1^{\text {low }}$ cohort $(\mathrm{p}=$ 0.036; Figure 1). Our results corroborate the findings of Facchinetti et al. as well as the findings in both glioblastoma and breast cancer, but more studies are needed to determine whether or not SphK1 expression is indicative of poorer prognosis in HNSCC [16,28-29].

Due to its retrospective nature, this paper is limited in scope. Future studies should include larger cohorts, with control of other variables such as HPV status or p53 positivity. Additionally, although we excluded patients who did not complete a course of radiation therapy, not every patient received the same dose of radiation. Although this is standard of care, it is possible that it affected the survival outcomes.

\section{Conclusion}

Sphingosine kinase 1 (SphK1) has previously been established as an important mediator of apoptosis, cell survival, and the proliferation of cancer cells. It is upregulated in cells showing increasing radioresistance. Our study indicates that higher expression of SphK1 correlates with poorer survival outcomes in patients with HNSCC of the oral cavity.

\section{REFERENCES}

[1] American Cancer Society, "Cancer Facts and Figures, 2012,” 2012.

http://www.cancer.org/acs/groups/content/@epidemiolog ysurveilance/documents/document/acspc-031941.pdf

[2] A. Argiris, M. V. Karamouzis, D. Raben and R. L. Ferris, "Head and Neck Cancer," Lancet, Vol. 371, No. 9625, 2008, pp. 1695-1709.

doi:10.1016/S0140-6736(08)60728-X

[3] B. Ogretmen and Y. A. Hannun, "Biologically Active Sphingolipids in Cancer Pathogenesis and Treatment," Nature Reviews Molecular Cell Biology, Vol. 4, No. 8, 2004, pp. 604-616. doi:10.1038/nrc1411

[4] Y. A. Hannun and L. M. Obeid, "Principles of Bioactive Lipid Signalling: Lessons from Sphingolipids," Nature Reviews Molecular Cell Biology, Vol. 9, No. 2, 2008, pp. 139- 150. doi:10.1038/nrm2329

[5] S. Spiegel and S. Milstien, "Sphingosine-1-Phosphate: An Enigmatic Signalling Lipid,” Nature Reviews Molecular Cell Biology, Vol. 4, No. 5, 2003, pp. 397-407. doi: $10.1038 / \mathrm{nrm} 1103$

[6] O. H. Lee, Y. M. Kim, Y. M. Lee, et al., "Sphingosine 1-Phosphate Induces Angiogenesis: Its Angiogenic Action and Signaling Mechanism in Human Umbilical Vein Endothelial Cells," Biochemical and Biophysical Research Communications, Vol. 264, No. 3, 1999, pp. 743-750. doi:10.1006/bbrc.1999.1586

[7] N. Bergelin, T. Blom, J. Heikkila, et al., "Sphingosine Kinase as an Oncogene: Autocrine Sphingosine 1-Phos- phate Modulates ML-1 Thyroid Carcinoma Cell Migration by a Mechanism Dependent on Protein Kinase CAlpha and ERK1/2,” Endocrinology, Vol. 150, No. 5, 2009, pp. 2055-2063. doi:10.1210/en.2008-0625

[8] D. Wang, Z. Zhao, A. Caperell-Grant, et al., "S1P Differentially Regulates Migration of Human Ovarian Cancer and Human Ovarian Surface Epithelial Cells,” Molecular Cancer Therapeutics, Vol. 7, No. 7, 2008, pp. 1993- 2002. doi:10.1158/1535-7163.MCT-08-0088

[9] L. Wang and S. M. Dudek, "Regulation of Vascular Permeability by Sphingosine 1-Phosphate," Microvascular Research, Vol. 77, No. 1, 2009, pp. 39-45. doi:10.1016/j.mvr.2008.09.005

[10] O. Cuvillier, G. Pirianov, B. Kleuser, et al., "Suppression of Ceramide-Mediated Programmed Cell Death by Sphingosine-1-Phosphate,” Nature, Vol. 381, No. 6585, 1996, pp. 800-803. doi:10.1038/381800a0

[11] T. Kohama, A. Olivera, L. Edsall, et al., "Molecular Cloning and Functional Characterization of Murine Sphingosine Kinase,” Journal of Biological Chemistry, Vol. 273, 1998, pp. 23722-23728. doi:10.1074/jbc.273.37.23722

[12] S. M. Mandala, R. Thornton, Z. Tu, et al., "Sphingoid Base 1-Phosphate Phosphatase: A Key Regulator of Sphingolipid Metabolism and Stress Response," Proceedings of the National Academy of Sciences of USA, Vol. 95, No. 1, 1998, pp. 150-155. doi:10.1073/pnas.95.1.150

[13] A. Olivera, T. Kohama, L. Edsall, et al., "Sphingosine Kinase Expression Increases Intracellular Sphingosine-1Phosphate and Promotes Cell Growth and Survival," Journal of Cell Biology, Vol. 147, No. 3, 1999, pp. 545558. doi:10.1083/jcb.147.3.545

[14] S. Spiegel and S. Milstien, "Functions of the Multifaceted Family of Sphingosine Kinases and Some Close Relatives,” Journal of Biological Chemistry, Vol. 282, No. 4, 2007, pp. 2125-2129. doi:10.1074/jbc.R600028200

[15] T. Kawamori, T. Kaneshiro, M. Okumura, et al., "Role for Sphingosine Kinase 1 in Colon Carcinogenesis," FASEB Journal, Vol. 23, No. 2, 2009, pp. 405-414. doi:10.1096/fj.08-117572

[16] J. R. Van Brocklyn, C. A. Jackson, D. K. Pearl, M. S. Kotur, P. J. Snyder and T. W. Prior, "Sphingosine Kinase-1 Expression Correlates with Poor Survival of Patients with Glioblastoma Multiforme: Roles of Sphingosine Kinase Isoforms in Growth of Glioblastoma Cell Lines,” Journal of Neuropathology \& Experimental Neurology, Vol. 64, No. 8, 2005, pp. 695-705. doi:10.1097/01.jnen.0000175329.59092.2c

[17] M. Vadas, P. Xia, G. McCaughan and J. Gamble, “The Role of Sphingosine Kinase 1 in Cancer: Oncogene or Non-Oncogene Addiction?” Biochimica et Biophysica Acta, Vol. 1781, No. 9, 2008, pp. 442-447.

[18] U. K. Sinha, V. J. Schorn, C. Hochstim, S. B. Chinn, S. Zhu and R. Masood, "Increased Radiation Sensitivity of Head and Neck Squamous Cell Carcinoma with Sphingosine Kinase 1 Inhibition,” Head \& Neck, Vol. 33, No. 2, 2010, pp. 178-188.

[19] R. Kolesnick and Z. Fuks, "Radiation and CeramideInduced Apoptosis,” Oncogene, Vol. 22, No. 37, 2003, pp. 
5897- 5906. doi:10.1038/sj.onc.1206702

[20] X. Deng, X. Yin, R. Allan, et al., "Ceramide Biogenesis Is Required for Radiation-Induced Apoptosis in the Germ Line of C. elegans,” Science, Vol. 322, No. 5898, 2008, pp. 110-115. doi:10.1126/science.1158111

[21] V. E. Nava, O. Cuvillier, L. C. Edsall, et al., "Sphingosine Enhances Apoptosis of Radiation-Resistant Prostate Cancer Cells,” Cancer Research, Vol. 60, No. 16, 2000, pp. 4468-4474.

[22] T. A. Taha, W. Osta, L. Kozhaya, et al., "Down-Regulation of Sphingosine Kinase-1 by DNA Damage: Dependence on Proteases and p53," The Journal of Biological Chemistry, Vol. 279, No. 19, 2004, pp. 20546-20554. doi:10.1074/jbc.M401259200

[23] A. E. Mahdy, J. C. Cheng, J. Li, et al., “Acid Ceramidase Upregulation in Prostate Cancer Cells Confers Resistance to Radiation: AC Inhibition, a Potential Radiosensitizer,” Molecular Therapy, Vol. 17, No. 3, 2009, pp. 430-438. doi:10.1038/mt.2008.281

[24] K. Shirai, T. Kaneshiro, M. Wada, et al., "A Role of Sphingosine Kinase 1 in Head and Neck Carcinogenesis,” Cancer Prevention Research, Vol. 4, No. 3, 2011, pp. 454-462. doi:10.1158/1940-6207.CAPR-10-0299
[25] R. Masood, I. Roy, S. Zu, et al., “Gold Nanorod-Sphingosine Kinase siRNA Nanocomplexes: A Novel Therapeutic Tool for Potent Radiosensitization of Head and Neck Cancer,” Integrative Biology, Vol. 4, No. 2, 2012, pp. 132-141. doi:10.1039/c1ib00060h

[26] F. Farshadpour, H. Kranenborg, E. V. Caikoen, et al., "Survival Analysis of Head and Neck Squamous Cell Carcinoma: Influence of Smoking and Drinking," Head \& Neck, Vol. 33, No. 6, 2011, pp. 817-823. doi:10.1002/hed.21549

[27] E. M. Sturgis, "The International Head and Neck Cancer Epidemiology Consortium,” Head \& Neck, Vol. 33, No. 1, 2011, p. 141. doi:10.1002/hed.21670

[28] M. M. Facchinetti, N. A. Gandini, M. E. Fermento, et al., "The Expression of Sphingosine Kinase-1 in Head and Neck Carcinoma,” Cells Tissues Organs, Vol. 192, No. 5, 2010, pp. 314-324. doi:10.1159/000318173

[29] E. Ruckhäberle, A. Rody, K. Engels, et al., "Microarray Analysis of Altered Sphingolipid Metabolism Reveals Prognostic Significance of Sphingosine Kinase 1 in Breast Cancer," Breast Cancer Research and Treatment, Vol. 112, No. 1, 2007, pp. 41-52. doi:10.1007/s10549-007-9836-9 